\title{
Adolescent units-wither on the vine? A meeting with the Under-secretary for State
}

\author{
Peter Wells
}

Concern is growing over the decline of services for disturbed young people, expressed in the correspondence columns of the British Medical Journal, in professional journals (Vanstraelen \& Cottrell, 1994; Saunders, 1993), and in literature from the Royal College of Psychiatrists (Pearce, 1994) among others. There has been a gradual loss of beds in adolescent psychiatric units, amounting in one survey of 60 units to nearly $20 \%$. At least seven units have closed all their beds, and others are threatened with closure.

This is taking place in spite of increasing demand. Department of Health (DOH) figures published in May 1994 show an increase in admissions to psychiatric units of 10 to 14 year olds in the period 1985 to 1990 of nearly $50 \%$. There is evidence that the incidence of depression, suicide in young men, eating disorders, sexual abuse and delinquency is on the increase. Waiting lists for clinics for young people have lengthened in $66 \%$ of units. In $58 \%$ it is from five to 13 weeks and in $10 \%$ the waiting time is over six months. The picture is one of an increasing demand on mental health services for young people in the face of a diminishing capacity to respond.

In a cash-drtven, rather than a needs-drtven. service it may seem disingenuous to ask how this has come about, but the reasons are complex.

Purchaser-provider split. Under the new financial arrangements, few, if any regional adolescent units can remain solvent through referrals from its parent district alone. Survival depends on cross-boundary flow from other districts. The priority for district managers, however, is their own district needs, whereas cross-boundary flow is financially unpredictable and risky. There is no cash indemnity to protect small regional units from the ebb and flow of referrals.

Purchasers don't know what is needed. A recently DOH-funded survey revealed that $48 \%$ of purchasers have no strategic plans whatsoever to meet the needs of mentally disturbed adolescents. Only $28 \%$ have such a strategy in use. A mere $13 \%$ (nine) had a basis for their specification which was based on an analysis of their population needs. The Health Advisory Service is currently surveying ten purchasing authorities, and a preliminary finding is that only one has a really sound strategy in place for meeting the mental health needs of young people. If after four years into the new market system. purchasers largely do not know what they want. the immediate future of costly adolescent units must be a bleak one.

Capital charges. The government levy capital charges on premises occupied by hospitals and NHS units. Adolescent units need plenty of floor space to contain energetic young people, so capital charges tend to be high in proportion to the number of beds. This renders many units relatively uncompetitive in the market, as capital charges have to be paid for in the amount charged for use of the beds.

Medical referrals only. Many units used to accept direct from medical and non medical sources. On my own unit, for example, social services referrals comprised around 25-30\% of the total. After the introduction of the purchaser/provider system, social services were no longer able to refer direct to the unit, but had first to persuade a medical source to accept the cost. This difficulty was compounded by the inevitable delay this caused. 
Recent Department of Health figures show that waiting times for clinics for disturbed young people have lengthened; $58 \%$ are now from five to 13 weeks and $10 \%$ are over six months. Referrals from non medical sources to my own unit declined to such an extent that the district decided to close it in March 1994.

'Community good, hospital bad' propaganda has led to reduced emphasis on investment in residential units. This ignores the fact that around 15 to $20 \%$ of referrals can only be effectively, safely and economically treated on such a unit (Wells, 1994).

Unfilled vacancies. The uncertainty over the future of adolescent units has led to difficulty in filling staff vacancies. The work is highly stressful. One unit had to close as a replacement for the retired consultant has not been found.

On 24 October 1994 a small group of three MPs, Ian McCartney, Mike Hall and Keith Bradley, and myself met the Parliamentary Under-secretary for State, John Bowis, to express these concerns. In the government response, the Minister has declined to impose a moratorium on the further closure of adolescent units. However, he is initiating a project "that will attempt to describe the data that can give guidance as to the numbers of children with difficult mental health problems likely to be found in districts with different demographic, socio-economic and cultural characteristics. It will set out what treatments have been demonstrated to be clearly effective in any particular condition". The DOH have also commissioned a needs assessment study, and plan a meeting with senior clinicians to identify key researchable questions.
These responses are to be welcomed, although it is doubtful whether practical solutions will emerge in time to prevent further erosion of the capacity of services to meet the overwhelming needs of damaged and mentally ill young people. There is a daunting feedback loop in these events: widespread concern-surveys of available services recommendations for improvements-delay in implementation because of lack of resources - new surveys needed as the earlier ones are out of date, etc. Only when this cycle is broken can a demoralised workforce begin to feel confident that the government recognises the scale of the problem.

Nevertheless the causes of the threat to regional adolescent units outlined above provide opportunities for government action which could salvage the situation and prevent further decline at least until the proposed research has been completed. Unfortunately, as with 'stuck' families embroiled in similar feedback loops, escape does depend on imaginative intervention from outside.

\section{References}

Pearce, J. (1994) Editorial comment. Child and Adolescent Section Newsletter, Royal College of Psychiatrists. Page 1

SAUNDERs, T. (1993) Adolescent units: can they survive? Young Minds Newsletter, 16, 18-19.

Vanstrallen, M. \& Cotrreu. D. (1994) Child and adolescent mental health services: purchasers' knowledge and plans. Brttish Medical Journal, 809. 259-261.

Weus, P. (1994) Treatment in the community? A very real dilemma. Young Minds Newsletter, 17, 19.

PETER Welus, Consultant to Mersey \& North West Regional Health Authority in Adolescent Psychiatry 1970-1992 